\title{
Percepções dos profissionais de saúde sobre a Estratégia Saúde da Familia: equidade, universalidade, trabalho em equipe e promoção da saúde/prevenção de doenças
}

\author{
Health professionals' perceptions about Family Health Strategy: equity, universality, team work and health
} promotion/disease prevention

\section{Percepciones de los profesionales de salud acerca de la Estrategia de Salud Familiar: equidad, universalidad, trabajo en equipo y la promoción de la salud/prevención de enfermedades}

Jacks Soratto. Programa de Pós-graduação em Enfermagem da Universidade Federal de Santa Catarina (UFSC). Florianópolis, SC, Brasil. jackssoratto@hotmail.com (Autor correspondente)

Regina Rigatto Witt. Programa de Pós-Graduação em Enfermagem da Universidade Federal do Rio Grande do Sul (UFRGS). Porto Alegre, RS, Brasil. witt@adufrgs.ufrgs.br

Denise Elvira Pires de Pires. Programa de Pós-Graduação em Enfermagem da Universidade Federal de Santa Catarina (UFSC). Florianópolis, SC, Brasil. piresdp@yahoo.com

Soraia Dornelles Schoeller. Departamento de Enfermagem da Universidade Federal de Santa Catarina (UFSC). Florianópolis, SC, Brasil. soraia@ccs.ufsc.br

Claudio Alex de Souza Sipriano. Programa de Residência Multiprofissional em Saúde Coletiva da Universidade do Extremo Sul Catarinense (UNESC), Criciúma - SC, Brasil. claudiocriciuma@yahoo.com.br

\section{Resumo}

Objetivo: analisar as percepções dos profissionais de atenção primária à saúde sobre a Estratégia Saúde da Família (ESF) em um município do sul do Brasil. Métodos: pesquisa qualitativa e exploratório-descritiva realizada com 15 trabalhadores da ESF. Os dados foram obtidos por meio da observação participante e de oficinas orientadas pelo Método Criativo Sensível, e analisados segundo a Análise Temática de Conteúdo. Resultados: as percepções dos profissionais enfatizaram duas categorias ligadas aos princípios do Sistema Único de Saúde (SUS) universalidade e equidade, e outras duas categorias vinculadas ao trabalho em equipe e à prevenção de doenças/promoção da saúde. Conclusão: as percepções dos profissionais sugerem a Estratégia Saúde da Família como local de difusão de ações curativas, mas também, de promoção da mudança do modelo vigente de cuidado em saúde.

\section{Abstract}

Objective: to analyze the perceptions of primary health staff about the Family Health Strategy (FHS) in a city of south of Brazil. Methods: a qualitative exploratory-descriptive study carried out with 15 workers of FHS. The data collection was obtained by participant observations and workshops oriented by the Creative Sensitive Method, followed by Thematic Content Analysis. Results: the study emphasized two categories linked to the principles of Brazilian National Health System (SUS), universality and equity, and two categories linked toteam work process and health promotion/disease prevention. Conclusions: The perceptions of workers indicated the Family Health as a place for primary prevention, but also for promoting a change to the current model of health care.

\section{Resumen}

Objetivo: analizar las percepciones de los profesionales de la atención primaria de salud sobre la Estrategia de Salud Familiar (ESF) en una ciudad del sur de Brasil. Métodos: investigación cualitativa y exploratorio-descriptivo, realizada con 15 trabajadores de la ESF. Los datos fueran obtenidos a través de la observación participante y talleres orientados por el Método Creativo Sensible, seguido de la Análisis Temático del Contenido. Resultados: las percepciones de los profesionales destacaron dos categorías relacionadas con los principios del Sistema Único de Salud: la universalidad y la equidad, y dos categorías vinculadas al processo de trabajo en equipo y a la prevención de enfermedades/promoción de la salud. Conclusiónes: la Estratégia Salud de la Familia es un lugar para el ejercicio de los principios y directrices del Sistema de Salud de brasileño y promueve el cambio del modelo de atención de la salud.

\section{Palavras-chave:}

Estratégia Saúde da Família Equidade em Saúde Prevenção de Doenças Promoção da Saúde Prevenção Primária

\section{Keywords:}

Family Health Strategy Equity in Health Disease Prevention Health Promotion Primary Prevention

\section{Palabras clave:}

Estrategia de Salud Familiar Equidad en Salud Prevención de Enfermedades Promoción de la Salud Prevención Primaria

Fonte de financiamento: O estudo foi custeado pelo primeiro autor deste manuscrito.

Parecer CEP:

UNESC 04/2010 de 10/03/2010.

\section{Conflito de interesses:} declaram não haver. Recebido em: 12/01/2014. Aprovado em: 06/01/2015. 


\section{Introdução}

As formas como se organizaram os serviços de saúde no Brasil não são resultado de um processo típico apenas do momento atual, mas sim, de um trabalho com uma longa trajetória de reformulaçôes e de lutas. De fato, tais organizaçôes foram inspiradas pelo movimento de reforma sanitária brasileira e, posteriormente, pelos reflexos produzidos pelo próprio processo de democratização da saúde. ${ }^{1}$

Essas lutas resultaram, na prática, em propostas contra-hegemônicas ao modelo de atenção à saúde, e se pautaram na busca de mudança do modelo assistencial. Esses embates resultaram na criação, em 1994, do Programa Saúde da Família, posteriormente chamado de Estratégia Saúde da Família (ESF). ${ }^{1-3}$

A ESF provocou alterações desde os padróes de financiamento até a reorganização da prática assistencial, ao propor uma compreensão ampliada do processo saúde/doença e a necessidade de intervenções que vão além de práticas tradicionais focadas na doença. ${ }^{1-4}$

A atuação da ESF está pautada em ações extramuros, respeitando um território pré-estabelecido, com responsabilização dos profissionais pelos impactos dos processos de atenção sobre a saúde e doença da população adstrita. ${ }^{2-4}$ No âmbito da reorganizaçấo dos serviços de saúde, a ESF vai ao encontro dos debates e análises referentes ao processo de mudança do paradigma médico-curativista, objetivando transformar o modo tradicional de prestação de assistência e estimular a implantação de um novo modelo assistencial de saúde. ${ }^{5-6}$

Outro objetivo da ESF é oportunizar a aquisição de novos valores que se pautam na promoção da saúde e na integralidade da assistência, para os quais é proposta a vinculação dos profissionais e dos serviços com a comunidade, juntamente com a perspectiva de promoção de açôes intersetoriais. ${ }^{4-7}$ Os profissionais de saúde são desafiados a reorientar suas práticas e a agregar à competência técnica conhecimentos e habilidades relacionados à dinâmica social e ao trabalho em equipe.

É nessa perspectiva que se coloca a possibilidade da ESF efetivar-se como re-orientadora do processo da prática assistencial. Os desafios da ESF são muitos, e explorá-los em todas as suas dimensôes é um exercício que se alicerça no cotidiano dos serviços e que avança transcendendo outras facetas do setor saúde.

Para compreender como a ESF vem sendo construída, sua influência e reflexos nas práticas em saúde, bem como se os princípios que a norteiam sustentam-se nos moldes preconizados pelo SUS, torna-se de fundamental importância refletir sobre a percepçáo que os próprios profissionais possuem sobre esses princípios. Diante do exposto, este estudo pretendeu responder à seguinte questão de pesquisa: Quais as percepções dos profissionais de saúde sobre a Estratégia Saúde da Família? Neste sentido, o presente estudo teve como objetivo analisar as percepçôes dos profissionais de saúde sobre a Estratégia Saúde da Família.

\section{Métodos}

O presente estudo compóe parte dos resultados da dissertação de mestrado do autor principal deste artigo e está alicerçado na corrente de pensamento compreensiva, ${ }^{8}$ que reconhece as realidades humanas como complexas, demandando do pesquisador a necessidade do contato com as pessoas nos seus próprios contextos sociais, e exigindo uma relação entre investigador e os sujeitos investigados, de modo que os resultados buscam explicitar a racionalidade do contexto dos atores estudados. ${ }^{8}$

Realizou-se uma pesquisa de campo, com abordagem qualitativa de caráter exploratório-descritivo. ${ }^{8}$ Os participantes do estudo foram 15 trabalhadores de uma ESF do sul do estado de Santa Catarina, escolhida de forma intencional. Os participantes foram: oito agentes comunitários de saúde, três técnicos de enfermagem, uma enfermeira, um médico, um odontólogo e um auxiliar de consultório dentário, identificados ao longo do texto pelas letras ESF seguidas de número cardinal, com o intuito de garantir o anonimato dos participantes.

A produção de informaçóes se deu através de discussão em grupo orientada pelo Método Criativo Sensível (MCS), ${ }^{9}$ e por meio da observação participante materializada através do diário de campo, que consistiu no registro da dimensão interpretativa das situações ocorridas no grupo. ${ }^{8}$ 
O referencial do MCS para producão das informaçôes se ancora no construtivismo crítico de Paulo Freire e consiste na discussão grupal (oficina) e em momentos de criatividade e sensibilidade. ${ }^{9}$ Supóe uma ação transformadora por meio da problematizaçáo pautada na construçáo coletiva e na pedagogia crítica-reflexiva, valorizando a singularidade de cada participante do grupo e a coletivização das experiências. ${ }^{9-10}$.

As oficinas foram realizadas na sala de reuniôes de equipe da ESF, e foram conduzidas pelo autor principal deste artigo. Contou também com a ajuda de um auxiliar de pesquisa que colaborou na parte organizacional, bem como no auxílio das anotaçóes das situaçôes significativas para o presente estudo, que acontenceram durante o transcurso da oficina. A materialização do MCS se deu através de uma oficina com uma duração de aproximadamente 1 hora e 35 minutos, dividida em cinco etapas:

Introdução: foi feita a apresentação e aproximação com a temática, e posteriormente realizou-se uma dinâmica inicial cujo objetivo era responder a uma questão motivadora:- "O que é para você a Estratégia Saúde da Família?”

Produção: consistiu na explicação e realização da Dinâmica de Sensibilidade e de Criatividade, intitulada "Livre para Criar" onde foram disponibilizados materiais de papelaria para que os participantes tivessem autonomia para representar individualmente a percepção sobre a temática proposta na oficina. A produção artística não foi objeto de análise. ${ }^{11}$

Apresentaçâo: consistiu na socialização entre os integrantes com suas percepçôes sendo coletivizadas de maneira espontânea no grupo, de acordo com a temática discutida no encontro. Os participantes apresentaram suas construçóes artísticas com os resultados da dinâmica inicial proposta na Introdução da oficina.

Discussão: dividiu-se em dois momentos. O primeiro momento consistiu na construção coletiva, na qual os participantes foram instigados pelo facilitador a construir uma percepçáo coletiva, orientados pela pergunta: - "O que é para o grupo a Estratégia Saúde da Família?” No segundo momento foi realizada a explanação da construção coletiva, com espaço para debate e com validação das informaçôes. Para consolidação da percepção do grupo foi disponibilizado papel pardo, pincel atômico, cola, tesoura entre outros materiais.

Avaliação: consistiu no fechamento do encontro, aproximando-se e distanciando-se da realidade dos participantes, pautada na seguinte pergunta: - "O que os participantes acharam da oficina?"

As informações foram analisadas após a transcrição do áudio das falas dos participantes no grupo, relacionando-as com as anotaçôes realizadas em diário de campo, mediante a "análise temática de conteúdo". ${ }^{12: 77}$ Neste tipo de análise, o objetivo é "descobrir os núcleos do sentido que compõem uma comunicação, cuja presença ou frequência signifiquem alguma coisa para o objeto analítico visado”. 8:316

A análise temática de conteúdo foi dividida em três fases: (1) pré-análise;(2) exploração do material; e (3) tratamento dos resultados obtidos: inferência e interpretação. ${ }^{12}$

Na primeira fase (pré-análise), foram realizadas "a escolha dos documentos a serem submetidos à análise, a formulação das hipóteses e dos objetivos, e a elaboração de indicadores que fundamentassem a interpretação final”. 12:125 De maneira prática, nesta fase foi feita a transcrição das entrevistas e a organização textual, digitada em um arquivo de texto "doc" do Word Microsoft Office.

$\mathrm{Na}$ segunda fase (exploração do material), objetivou-se alcançar o aspecto central de compreensão do texto, em uma "fase longa e fastidiosa, que consiste essencialmente em operaçôes de codificaçôes, decomposição ou numeração". 12:131 Nesta etapa foram construídas as codificaçôes mediante as expressôes ou palavras significativas, que posteriormente geraram as categorias.

$\mathrm{Na}$ terceira fase (tratamento dos resultados obtidos), ocorreu a inferência e a interpretação dos conteúdos, buscando inter-relacioná-los juntamente com a percepção do pesquisador e o alicerce teórico que sustenta o estudo. É importante destacar que os trechos das entrevistas utilizados para a realizaçáo das inferências, foram os mais representativos das categorias de resultados.

Quanto aos procedimentos éticos, foram respeitadas as diretrizes legislativas vigentes. ${ }^{13}$ Paralelamente aos contatos preliminares e inserção no campo para divulgação do projeto de pesquisa, o mesmo foi encaminhado para a Comissão de Pesquisa da Escola de Enfermagem da Universidade Federal do Rio Grande do Sul e ao Comitê de Ética e Pesquisa da Universidade do Extremo Sul Catarinense (UNESC) (parecer favorável nº 04/2010). 


\section{Resultados e discussão}

A transcrição das informaçôes gerou 166 codificaçôes, que foram classificadas em sete categorias empíricas. Devido ao fato deste artigo ser resultado de uma parte da dissertação de mestrado do primeiro autor, serão aqui apresentadas somente três categorias, sendo que as duas primeiras estáo associadas aos princípios e diretrizes do SUS e a última mais vinculada ao modo operante das práticas assistenciais dos profissionais da ESF.

\section{A equidade e a universalidade na Estratégia Saúde da Família}

Os participantes perceberam a ESF como instrumento para a efetivaçáo dos princípios constitucionais, denotando a importância da grande maioria dos princípios [filosóficos e organizativos] que norteiam o SUS, como exemplificado nas falas abaixo.

Abranger saúde, ao alcance de toda a população (ESF01).

[...] igualdade a todos hoje, porque antes, no meu ponto de vista, não era igual. O SUS, digo, a saúde, não era para todos. Hoje a saúde é para pobre e rico, tudo igual (ESF02).

Eu acho que tem que ter igualdade entre as pessoas, pois às vezes não tem (ESF15).

Os participantes identificaram a ESF como uma ferramenta para a aplicabilidade dos preceitos que regem o SUS. Ao analisar a palavra equidade numa ótica semântica, esta pode ser entendida em aproximaçáo com a igualdade, como dito no depoimento, porém não são termos sinônimos apesar da fala representar um dos significados da equidade. Apesar de todos terem direito de acesso aos serviços, independente de cor, raça ou religião e sem nenhum tipo de privilégio, as pessoas não são iguais e, por isso, têm necessidades de saúde distintas. ${ }^{14}$

As falas anteriores trazem à tona avanços resultantes do SUS, principalmente com a implementação da ESF, enfatizando as dificuldades de fornecimento de um atendimento equânime e universal antes da democratização do setor da saúde. Elas também indicam fragilidades e aspectos a serem revistos e melhor discutidos quanto à aplicação deste princípio no locus de atuação dos profissionais.

A equidade fomenta a promoçáo desta igualdade, identificando desigualdades que atingem os sujeitos, contudo deve ir além de um princípio filosófico do sistema para ser incorporada como fundamento ético nas rotinas da ESF. ${ }^{14}$ É a luta pela igualdade que os participantes trazem em suas falas, já que eles observam as desigualdades prevalentes nas práticas assistenciais.

Outro princípio ressaltado foi a universalidade, aqui entendida como cobertura de toda a populaçáo, através do acesso equânime à saúde em todos os níveis de assistência, sem preconceitos ou privilégios de qualquer espécie:

Claro que isso não é tão fácil de conseguir, mas abranger saúde, ao alcance de todas as pessoas da população é fundamental (ESF01).

Apesar das dificuldades para a universalização, os participantes percebem a ESF como uma possibilidade de efetivar esse princípio, que caracteriza a saúde como um direito à cidadania, abrangendo a cobertura, o acesso e o atendimento nos serviços do SUS e exprimindo a ideia de que o Estado tem o dever de atender a toda população. ${ }^{15}$ Esse acesso a toda população é visto também no cotidiano dos profissionais de saúde da ESF através da assistência as famílias:

É um programa que exige dedicação [...] cuidado com a família em uma determinada área de abrangência (ESF09).

A dedicação e o acolhimento foram alguns dos elementos que os participantes consideraram importantes para alcançar, do ponto de vista mais prático, a efetivação da equidade e da universalidade. Esta satisfaçáo do usuário, mediante a oferta de ações e serviços mais adequados, tendo por base o acolhimento, oportuniza melhorias quanto ao acesso. ${ }^{16}$

Os princípios da equidade e da universalidade são elementos interpeladores das políticas de saúde e também das práticas cotidianas do processo de trabalho. A percepção desses princípios, tal como apresentado, sugere a ESF como local fomentador do direito à saúde e de superação da tradicional estrutura de organização dos serviços. 


\section{0 trabalho em equipe e as formas de compreendê-lo}

Outra percepção dos profissionais de saúde sobre a ESF refere-se aos aspectos relacionados ao trabalho em equipe, sendo este considerado um dos pilares mais importantes para a efetividade da ESF.-17 $\mathrm{O}$ trabalho em equipe foi observado por meio de duas óticas: em uma, foi evidenciada a importância do trabalho dos diferentes profissionais isoladamente; em outra, considerou-se a noção mais ampla do trabalho em equipe como articulador de saberes.

Na Estratégia Saúde da Família, tem o trabalho das agentes comunitárias de saúde, da enfermeira, trabalhos de triagem e o trabalho do médico. Tem que trabalhar em equipe multidisciplinar, várias pessoas, cada uma fazendo a sua parte, mas também ajudando a equipe para formar um trabalho de grupo (ESF04).

A primeira percepção denota que os profissionais de saúde atuam em espaços individuais de trabalho, desenvolvendo açóes de relativa independência e com poucas possibilidades de interação. O trabalho em equipe é caracterizado tão somente pela justaposição das várias profissôes em torno de um mesmo problema, sem o estabelecimento de relações entre os profissionais representantes de cada área. Mesmo se referindo à necessidade de responsabilidade no trabalho em equipe, esta pode continuar sendo individualizada segundo a competência profissional de cada trabalhador. Esse tipo de entendimento na prática profissional pode "se tornar um obstáculo para a aplicabilidade do princípio da integralidade", pois a agregação profissional em si não efetiva a integralidade na prática dos serviços. ${ }^{18}$

A seguir, os participantes trouxeram outra percepção para a integralidade, pautada na intersecção de saberes, e é sobre essas intersecçôes que surge outro sentido para a integralidade, que pode entấo estar vinculada ao trabalho em equipe, analogicamente ilustrando a necessidade de unidade e sincronismo na prática cotidiana da ESF, conforme o seguinte depoimento:

A Estratégia de Saúde da Família é o trabalho em equipe, que são os elos, que significam uniáo como se fosse uma aliança (ESF04).

A analogia feita entre "equipe" e "elos" leva a refletir sobre a importância do sentido da integralidade na prática dos serviços em saúde. O trabalho em saúde é um trabalho coletivo e é essa interatividade que o trabalho exige, o que náo impede a manifestação da individualidade. ${ }^{19}$

Os elos significam os próprios profissionais de saúde, envoltos por seus saberes e crenças, que, de certa forma, se individualizam, mas que precisam ficar ligados a outros saberes e a outros indivíduos. Tais elos podem ser diferentes em formas, espessuras, tipo de material, mas o ponto comum é a união das diferenças, pois é mediante a convivência com os diferentes que se pode melhor lutar contra os antagônicos. ${ }^{20} A s s i m$, é em meio à junção dessas diferenças técnicas, culturais e econômicas que se criam forças coletivas para a transformação das práticas antagônicas que prevalecem no cotidiano da ESF, elementos impedidores de uma saúde mais integral.

É incontestável a importância do trabalho em equipe na ESF devido ao fato de o mesmo possibilitar a integralidade nos cuidados de saúde. Assim, a integralidade pode ser considerada como um termo polissêmico, com sentidos variados. Na discussão da integralidade, ressalta-se que o trabalho em equipe é um dos caminhos para a aproximação a este princípio, especialmente quando a reflexão é feita a partir da articulação do trabalho de cada profissional. ${ }^{21}$

\section{A prevenção de doenças e a promoção da saúde}

Os participantes associaram a ESF primeiramente a aspectos relacionados à prevenção de doenças, com a centralidade das açốes em consultas e exames e a seguir, a promoção da saúde, por meio de hábitos de vida saudáveis e vinculada à educação para a não doença. A seguinte fala enfatiza a primeira percepção:

Prevenir através de alguns exames e diagnosticar algumas doenças prematuramente (ESF01).

Apesar dessa percepção representar uma das atribuiçóes técnicas da ESF, o entendimento que se teve mediante as outras inúmeras falas foi que os participantes compreendem a ESF como uma ferramenta para a náo doença. Embora a prevenção de doenças seja fundamental na assistência prestada pelos profissionais de saúde e fator importante para a legitimaçáo do princípio constitucional de direito à saúde e do ser saudável, ficou evidente a centralidade da doença nas açóes assistenciais. 
A lógica da doença no cotidiano da ESF pode se tornar um obstáculo para os profissionais discernirem o momento do encontro sobre outro prisma que não seja a ótica fragmentária e curativista, característica do modelo biomédico. ${ }^{5}$ Essa predominância dificulta possibilidades de se contemplar o sujeito em sua totalidade nesses encontros. A fragmentação do ser, tipificada pela preocupaçáo com a doença, pode tornar-se mais importante do que a composiçáo dos diferentes aspectos que integram o sujeito.

Desse modo, a complexidade do contexto social, histórico e cultural dos indivíduos tende a ser desconsiderada, isolando os diversos aspectos holísticos que participam para a manutenção e busca do ser saudável. Além disso, propaga-se uma noção do que os profissionais consideram como sendo um comportamento correto, pressupondo este como fonte legítima de verdade. ${ }^{5}$

A segunda percepção dos participantes que se vinculou a essa categoria foi a promoção da saúde, conforme descrito na seguinte fala:

[...] promoção da saúde, ensinando às crianças a maneira certa de escovação, conscientizando sobre a alimentação, visando à saúde (ESF04).

A promoção da saúde representa uma estratégia promissora para se enfrentarem os múltiplos problemas de saúde que afetam as populaçóes. A Política Nacional de Atenção Básica (PNAB) confere um papel importante à Promoção da Saúde no conjunto de ações sobre a responsabilidade da atenção primária a saúde (APS) e, em especial, da ESF.22 Apesar de possuírem uma visão mais ampla do que a prevenção de doenças, o que chama a atenção é o como os participantes entendem as formas de exercer as açôes de promoção da saúde, essas pautadas prioritariamente na:

[...] conscientização do problema pra evitar que aconteça [doença] (ESF06).

A promoção da saúde por meio de orientaçôes para determinados grupos, pautada nas necessidades de ensino na conscientização sobre práticas "corretas" de se viver, é uma das açôes importantes no processo de trabalho, entretanto, a forma como se materializa pressupóe uma superioridade dos profissionais de saúde, tipificando que somente eles detêm o conhecimento. ${ }^{23}$

[...] um grupo falando sobre escovação, como ele [o dente] é escovado, e quais são os cuidados, que muitos não têm conhecimento (ESF08).

Ao considerarem que muitos usuários não têm conhecimento, os participantes admitem que só os profissionais o possuem, o que pode caracterizar a chamada educaçáo bancária. ${ }^{10}$ Essa prática também pode negar ao usuário a deliberação e o desejo para exercer seu direito de participar da assistência e, consequentemente, para formular seu plano de conquista da saúde (por direito) naquele micro espaço de atuação e não apenas no legalmente constituído (conselho e conferência). Nesse processo de educação, os usuários podem ser vistos como seres passivos e sem domínio da realidade, sendo os profissionais de saúde (educadores) os sujeitos do processo, e os usuários (educandos) meros objetos. ${ }^{10}$

A incorporação por parte dos profissionais da prerrogativa de ir ao encontro ao comportamento do sujeito reforça uma postura de culpabilização, o que fortalece a submissão do usuário e sua negaçáo como agente criador construtor do seu espaço. ${ }^{5}$ Tal prática se dá mediante uma pedagogia de transmissão de conhecimento que restringe o comportamento correto naquilo que os profissionais difundem, colocando nas mãos do sujeito a responsabilidade pela sua condição de saúde e doença e, também, de invalidação dos conhecimentos postos em prática na vida cotidiana.

\section{Conclusão}

Os profissionais de saúde participantes do presente estudo perceberam a ESF como um local para consolidar determinados princípios filosóficos do SUS, valorizando a luta pela conquista do direito à saúde e, consequentemente, ampliando os horizontes de sua atuação ao identificarem a ESF como um local para a prática da universalidade, equidade e trabalho em equipe.

Por outro lado, apesar de importante para assistência, os usuários aproximaram a ESF dos aspectos que a vinculam às práticas fragmentárias do modelo biomédico de saúde, compreendendo-as como açóes que visam evitar e combater as doenças mediante uma postura profissional verticalizada.

O fato de os participantes trazerem elementos que norteiam os princípios filosóficos do SUS sugere a ESF como uma alternativa estruturante para reordenação do modelo de atenção à saúde. Além disso, mesmo diante de algumas limitaçóes quanto à própria concepção de assistência à saúde, a ESF ainda tem sido um dos poucos instrumentos possíveis para a transformação das formas de pensar e produzir saúde no Brasil. 
As percepçóes encontradas no presente estudo sugerem avanços quanto ao entendimento do significado da ESF, mas também indicam aspectos que precisam ser aperfeiçoados para uma concepção assistencial diferenciada e de respeito ao sujeito, seja nos cotidianos das equipes, no processo de gestão e até na formação dos profissionais.

\section{Referências}

1. Mendes EV. O cuidado das condições crônicas na atenção primária à saúde: o imperativo da consolidação da estratégia da saúde da família. Brasília: Organização Pan-Americana da Saúde; 2012.

2. Araujo MBS, Rocha PM. Trabalho em equipe: um desafio para a consolidação da estratégia de saúde da família. Ciênc Saúde Coletiva. 2007;12(2):455-464. http://dx.doi.org/10.1590/S1413-81232007000200022.

3. Sipriano CAS. Educação Popular: círculos de cultura e os limites e as possibilidades de empowerment do conselho local de saúde [dissertação]. Criciúma: Universidade do Extremo Sul Catarinense; 2012. 121 p.

4. Paim JS. A reforma sanitária brasileira e o Sistema Único de Saúde: dialogando com hipóteses concorrentes. Physis. 2008;18(4):625-644. http://dx.doi.org/10.1590/S0103-73312008000400003.

5. Guedes CR, Nogueira MI, Camargo JRKR. A subjetividade como anomalia: contribuições epistemológicas para a crítica do modelo biomédico. Ciênc Saúde Coletiva. 2006;11(4):1093-1103. http://dx.doi.org/10.1590/S141381232006000400030.

6. Conill EM. Ensaio histórico-conceitual sobre a Atenção Primária à Saúde: desafios para a organização de serviços básicos e da Estratégia Saúde da Família em centros urbanos no Brasil. Cad Saúde Pública. 2008;24(1):7-16. http://dx.doi.org/10.1590/S0102-311X2008001300002.

7. Soratto J, Witt RR. Participação e controle social: percepção dos trabalhadores da saúde da família.Texto Contexto Enferm. 2013;22(1):89-96. http://dx.doi.org/10.1590/S0104-07072013000100011.

8. Minayo MCS. Desafio do conhecimento: pesquisa qualitativa em saúde. São Paulo: Hucitec; 2010.

9. Cabral IE. Uma abordagem criativo e sensível de pesquisa a família. In: Althoff CR, Elsen I, Nietschke RG, editors. Pesquisando a família: olhares contemporâneos. Florianópolis: Papa-livros; 2004. p. 127-140.

10. Freire RP. Pedagogia do Oprimido. São Paulo: Paz e Terra; 2005.

11. Issi HB, Motta MGC, Ribeiro NRR. Método criativo sensível: uma alternativa para pesquisar famílias. In: Anais Congresso Íbero-Americano de Investigação Qualitativa em Saúde, 2008 May 8-9; Porto Rico. Porto Rico: Escola Graduada de Saúde Pública; 2008.

12. Bardin L. Análise de conteúdo. São Paulo: Edições 70; 2011.

13. Ministério da Saúde (BR), Conselho Nacional de Saúde. Resolução n. 466, de 12 de dezembro de 2012. Diretrizes e normas regulamentadoras de pesquisa envolvendo seres humanos. Brasília: Ministério da Saúde; 2012. Disponível em: http://conselho.saude.gov.br/resolucoes/2012/Reso466.pdf

14. Vieira-da-Silva LM, Almeida Filho N. Eqüidade em saúde: uma análise crítica de conceitos. Cad Saúde Pública. 2009;25(2):217-226. http://dx.doi.org/10.1590/S0102-311X2009001400004

15. Viegas FSM, Penna MMC.O SUS é universal, mas vivemos de cotas. Ciênc Saúde Coletiva. 2013;18(1):181-190. http://dx.doi.org/10.1590/S1413-81232013000100019

16. Nora RDC, Junges RJ.Política de humanização na atenção básica: revisão sistemática. Rev Saúde Pública. 2013;47(6):1186-1200. http://dx.doi.org/10.1590/S0034-8910.2013047004581

17. Camargo Jr KR, Campo EMS, Teixeira MTB, Mascarenhas MTM, Mauad NM, Franco TB, et al. Avaliação da atenção básica pela ótica políticoinstitucional e da organização da atenção com ênfase na integralidade. Cad Saúde Pública. 2008;24(1):58-68. http://dx.doi.org/10.1590/S0102-311X2008001300011.

18. Gomes RS, Pinheiro R, Guizard FL. A orquestração do trabalho em saúde: um debate sobre a fragmentação das equipes. In: Pinheiro R, Mattos RA, editors. Construção social da demanda: direito à saúde, trabalho em equipe, participação e espaços públicos. Rio de Janeiro: Associação Brasileira de Saúde Coletiva; 2010. p.107-118.

19. Pires D. A enfermagem enquanto disciplina profissão e trabalho. Rev Bras Enferm. 2009;62(5):739-744. http://dx.doi.org/10.1590/S0034-71672009000500015.

20. Freire PR. Pedagogia da esperança: um reencontro com a pedagogia do oprimido. Rio de Janeiro: Paz e Terra; 1997.

21. Mattos RA. A integralidade na prática (ou sobre a prática da integralidade). Cad Saúde Pública. 2004;20(5):1411-1416. http://dx.doi.org/10.1590/S0102-311X2004000500037.

22. Ministério da Saúde (BR). Portaria n².488, de 21 de outubro de 2011. Aprova a Política Nacional de Atenção Básica, estabelecendo a revisão de diretrizes e normas para a organização da Atenção Básica, para a Estratégia Saúde da Família (ESF) e o Programa de Agentes Comunitários de Saúde (PACS). Brasília: Ministério da Saúde; 2011. http://bvsms.saude.gov.br/bvs/saudelegis/gm/2011/prt2488_21_10_2011.html.

23. Roecker S, Budó MLD, Marcon SS. Trabalho educativo do enfermeiro na Estratégia Saúde da Família: dificuldades e perspectivas de mudanças. Rev Esc Enferm USP. 2012;46(3):641-649. http://dx.doi.org/10.1590/S0080-62342012000300016 